\title{
Study on the Influence of Floating Population on Urban Economic Growth
}

\author{
Shuwei Chen ${ }^{1, a}$ Jingfeng Zhao ${ }^{2, b}$ and Zhaoan $\operatorname{Han}^{3, c}$ \\ ${ }^{1}$ Research Center of Western China's Economic Development, Northwest University, shaanxi, \\ xi 'an,China \\ ${ }^{2}$ Research Center of Western China's Economic Development, Northwest University, shaanxi, \\ xi 'an,China \\ ${ }^{3}$ School of Economics \& Management, Northwest University, Xi'an China \\ aashuweichen@126.com, b171545892@qq.com, ${ }^{\mathrm{a}} 790833409 @ q q . c o m$
}

Keywords: Floating population; Economic growth

\begin{abstract}
In 2016, the total number of floating population is 245 million, and the inflow of floating population can greatly increase the vitality of cities and promote urban economic growth. Articles based on solow growth - swan model, the effective labor model, the human capital is divided into local human capital and human capital flow, and the launch of the floating population of urban economic growth contribution rate, theoretically proved the floating population of urban economic growth contribution. In addition, it is also learned that the greater the contribution to economic growth is not the more floating population, but the flexibility related to the human capital of the floating population to the economic growth. Accordingly, relevant Suggestions are put forward.
\end{abstract}

\section{Introduction}

Population flow as a particular kind of social phenomenon, has always been the hot spot of the scholars study areas, especially in our country is in economic transition, the important period for the construction of urbanization, a large number of floating population influx into the national center for urban and regional central city. The influx of floating population brings vitality and vitality to the city, and it is a powerful impetus for China's urbanization to become an indispensable part of urban economic construction. The floating population will undoubtedly promote the city's economic construction and the existing research mainly focused on the floating population to study the influence of urban economic growth, the floating population to study the contribution of economic growth did not get the attention they deserve, in this paper, based on a economic growth model, the effective labor model analysis of the floating population of urban contribution rate of economic growth.

\section{Literature review}

The floating population is a concept under the conditions of China's household registration system, which refers to the population that has left the registered residence to live in other places, but there is no clear, accurate and unified definition. Internationally, similar groups are known as internB1 migrBtion.

The existing theories of population flow mainly include: marxist theory of population flow, traditional model of development economics, new labor migration economics, population migration theory, and push-pull theory. Marxist theory of population flow analyses the causes and dynamics of population flow and reveals the law of population flow ${ }^{[1]}$. The economic development school believes that the imbalance between urban and rural economic growth in developing countries and unbalanced economic opportunity inevitably lead to the simultaneous growth of rural population into cities and cities. Relying on industrial expansion alone cannot solve the problem of urban unemployment in developing countries; Controlling the scale and speed of rural population like urban flow can solve the urban unemployment problem in developing countries ${ }^{[2]}$. New economics of Labour migration that migrants should consider the calculation of the expected income income 
variability direct loss for personal utility, and the effect of the variability in rural and urban income for the future ${ }^{[3]}$. The theory of push-pull is that the root cause of population migration lies in the combination of "thrust" and "pull" of the former residence, and the migration ${ }^{[4]}$.

Research achievements of floating population impact on economic growth is rich, fang CAI and de-wen wang (1999) put forward China's labor migration brings resource reconfiguration, keep the comparative advantage, fill the blank of the jobs and promote the development of urban construction and so on four effect ${ }^{[5]}$. Tsu-hui Yang and Xiao Zhenyu (1996) argues that migration is to speed up the construction of urbanization in our country are large thrust, a round trip to the floating population of urban civilization, economic information spread to rural areas, such as population urbanization indirectly promote ${ }^{[6]}$. Duan Ping zhong (2008) points out that population flow on the effect of convergence between regions is very big, he pointed out that during the period of 1996 to 2003, the country's population flow to speed up the economic growth, central and western parts of the country's spread speed, and exacerbating the facts of the widening gap between these $\operatorname{areas}^{[7]}$.

\section{The theoretical model of the contribution rate of floating population to urban economic growth}

Analysis of factors that affect economic growth. The theory of economic growth generally refers to the increasing process of social material wealth, which also refers to the commonality of the dynamic process of general social reproduction. It is generally believed that the factors that affect economic growth include technology, capital, labor, natural resources and so on. Resource constraints. Resources are the general name of various resources including capital, labor quality and natural resources. Technical constraints. Technological progress has always been an important factor in economic growth, technology generally includes entrepreneurial talents, management ability, scientific and technological progress, the progress of technology can greatly promote economic growth, that is why say technology is the first productive force. System constraints. In addition to the above resource constraints and technical constraints, organizational constraints are also an aspect.

Factors affect the basic principles of economic growth. In this paper, the production function factor method is used to study the contribution of each factor to economic growth. The production function factor method is the mathematical model of the relationship between the production factors and the maximum output quantity of the production factors that are put into production during the production process. The specific formula is as follows:

$$
P_{t}=B_{t} F\left(G_{t}, L_{t}\right)=B_{t} L^{\beta} G^{\alpha}
$$

Take the differential of time $t$ on both sides of the above production function, and get the following expression:

$$
\frac{\partial \mathrm{P}}{\partial \mathrm{t}}=\frac{\partial \mathrm{B}_{\mathrm{t}}}{\partial \mathrm{t}} \mathrm{F}\left(\mathrm{G}_{\mathrm{t}}, \mathrm{L}_{\mathrm{t}}\right)+\mathrm{B}_{\mathrm{t}} \frac{\partial \mathrm{F}}{\partial \mathrm{G}_{\mathrm{t}}} \frac{\partial \mathrm{G}_{\mathrm{t}}}{\partial \mathrm{t}}+\mathrm{B}_{\mathrm{t}} \frac{\partial \mathrm{F}}{\partial \mathrm{L}_{\mathrm{t}}} \frac{\partial \mathrm{L}_{\mathrm{t}}}{\partial \mathrm{t}}
$$

Divide both sides of the expression by the left and right sides of the production function.

$$
\frac{\partial \mathrm{P}}{\partial \mathrm{t} \times \mathrm{P}_{\mathrm{t}}}=\frac{\partial \mathrm{B}_{\mathrm{t}}}{\partial \mathrm{t} \times \mathrm{B}_{\mathrm{t}}}+\frac{\partial \mathrm{F}}{\partial \mathrm{G}_{\mathrm{t}} \times \mathrm{F}} \frac{\partial \mathrm{G}_{\mathrm{t}}}{\partial \mathrm{t}}+\frac{\partial \mathrm{F}}{\partial \mathrm{L}_{\mathrm{t}} \times \mathrm{F}} \frac{\partial \mathrm{L}_{\mathrm{t}}}{\partial \mathrm{t}}
$$

Deformation is:

$$
\frac{\partial \mathrm{P}}{\partial \mathrm{t} \times \mathrm{P}_{\mathrm{t}}}=\frac{\partial \mathrm{B}_{\mathrm{t}}}{\partial \mathrm{t} \times \mathrm{B}_{\mathrm{t}}}+\frac{\partial \mathrm{F}}{\partial \mathrm{G}_{\mathrm{t}}} \frac{\mathrm{G}_{\mathrm{t}}}{\mathrm{F}} \frac{\partial \mathrm{G}_{\mathrm{t}}}{\partial \mathrm{t} \times \mathrm{G}_{\mathrm{t}}}+\frac{\partial \mathrm{F}}{\partial \mathrm{L}_{\mathrm{t}}} \frac{\mathrm{L}_{\mathrm{t}}}{\mathrm{F}} \frac{\partial \mathrm{L}_{\mathrm{t}}}{\partial \mathrm{t} \times \mathrm{L}_{\mathrm{t}}}
$$

$\frac{\partial \mathrm{F}}{\partial \mathrm{G}_{\mathrm{t}}} \frac{\mathrm{G}_{\mathrm{t}}}{\mathrm{F}}$ and $\frac{\partial \mathrm{F}}{\partial \mathrm{L}_{\mathrm{t}}} \frac{\mathrm{L}_{\mathrm{t}}}{\mathrm{F}}$ It is the elasticity of capital and labo, $\frac{\partial \mathrm{F}}{\partial \mathrm{G}_{\mathrm{t}}} \frac{\mathrm{G}_{\mathrm{t}}}{\mathrm{F}}=\alpha, \frac{\partial \mathrm{F}}{\partial \mathrm{L}_{\mathrm{t}}} \frac{\mathrm{L}_{\mathrm{t}}}{\mathrm{F}}=\beta$, Because the solloswann model assumes that scale compensation is constant, so, $\alpha+\beta=1$, The above formula can be written as: 


$$
\frac{\dot{\mathrm{P}_{\mathrm{t}}}}{\mathrm{P}_{\mathrm{t}}}=\frac{\dot{\mathrm{B}_{\mathrm{t}}}}{\mathrm{B}_{\mathrm{t}}}+\alpha \frac{\dot{\mathrm{G}_{\mathrm{t}}}}{\mathrm{G}_{\mathrm{t}}}+\beta \frac{\dot{\mathrm{L}_{\mathrm{t}}}}{\mathrm{L}_{\mathrm{t}}}
$$

To apply the equation to discrete data, the upper equation is the difference equation:

$$
\frac{\Delta \mathrm{P}_{\mathrm{t}}}{\mathrm{P}_{\mathrm{t}}}=\frac{\Delta \mathrm{B}_{\mathrm{t}}}{\mathrm{B}_{\mathrm{t}}}+\alpha \frac{\Delta \mathrm{G}_{\mathrm{t}}}{\mathrm{G}_{\mathrm{t}}}+\beta \frac{\Delta \mathrm{L}_{\mathrm{t}}}{\mathrm{L}_{\mathrm{t}}}
$$

$\frac{\Delta B_{t}}{B_{t}}$ for technical progress, represents the contribution of technological progress to economic growth; $\alpha \frac{\Delta \mathrm{G}_{\mathrm{t}}}{\mathrm{G}_{\mathrm{t}}}$ for capital contribution to economic growth, $\beta \frac{\Delta \mathrm{L}_{\mathrm{t}}}{\mathrm{L}_{\mathrm{t}}}$ the contribution rate of labor to economic growth.

Effective labor model. This paper USES a modified cobb-douglas production function effective labor model, before the introduction of effective labor model, therefore, it is necessary to introduce cobb-douglas production function.

According to the definition of economics, production function is to describe the production process of combination of various factors of production into the dependent relationship between production and the possible maximum yield of mathematical functions, including the input of production factors such as technology, capital and labor ${ }^{[8]}$. Cobb and Douglas, the American economists, coined the term "production function" in 1928, and used 33 years of production data to derive the famous cobb-douglas production function. In the study of economics, the cobb-douglas function has been widely used, leading to a long lasting situation. In the process of scholars' research and application, new research results have emerged, including the effective labor model used in this paper.

The effective labor model is to integrate the human capital concept of schultz and becker into the economic growth model, introducing the human capital level factor of labor force, and its basic expression is:

$$
P_{t}=B_{t} G_{t}^{\alpha} H_{t}^{\beta}
$$

The new growth equation can be obtained by the same procedure as above:

$$
\frac{\Delta \mathrm{P}_{\mathrm{t}}}{\mathrm{P}_{\mathrm{t}}}=\frac{\Delta \mathrm{B}_{\mathrm{t}}}{\mathrm{B}_{\mathrm{t}}}+\alpha \frac{\Delta \mathrm{G}_{\mathrm{t}}}{\mathrm{G}_{\mathrm{t}}}+\beta \frac{\Delta \mathrm{H}_{\mathrm{t}}}{\mathrm{H}_{\mathrm{t}}}
$$

$\beta \frac{\Delta \mathrm{H}_{t}}{\mathrm{H}_{t}}$ representing human capital is the contribution rate of effective labor to economic growth.

The mechanism of economic growth is influenced by floating population. For the floating population to measure the contribution of economic growth, labor capital in the production function is decomposition, divided into the local population and floating population, and on this basis for the following analysis. This article assumes the following assumptions:

(1)The floating population has full employment in the urban areas.

(2)The total labor force in Beijing is made up of two parts, one of which is the local labor force $\mathrm{H}_{1}$ and the other part of the field labor force $\mathrm{H}_{2}$, and $\mathrm{H}=\mathrm{H}_{1}+\mathrm{H}_{2}$;

(3)The local labor force $\mathrm{H}_{1}$ and the migrant labor force $\mathrm{H}_{2}$ are independent of each other;

(4)The technique is invariant, that is, technology is exogenous variables.

Based on the above introduction to the model, this paper constructs the following model:

$$
\mathrm{P}_{\mathrm{t}}=\mathrm{BG}_{\mathrm{t}}^{\alpha} \mathrm{H}_{1}^{\beta} \mathrm{H}_{2}^{\gamma}
$$

$\mathrm{H}_{1}^{\beta}$ is local human capital stock of $\mathrm{t}$ period: $\mathrm{H}_{2}^{\gamma}$ is the human capital stock of urban floating population in t period will take the logarithm of both sides:

$$
\ln \mathrm{P}_{\mathrm{t}}=\mathrm{B}+\alpha \ln \mathrm{G}_{\mathrm{t}}+\beta \ln \mathrm{H}_{1}+\gamma \ln \mathrm{H}_{2}
$$

In this case, because we assumed that the technology was the same, so $B=0 ; \alpha$ 、 $\beta$ 、 $\gamma$ All parameters to be estimated, respectively fixed capital, local human capital and human capital stock 
of the floating population of output elasticity, the sign says the elements of the direction of the output function, if is, say have a promoting effect on output, if negative, said has inhibitory effect on output; And size indicates the intensity of its action;if $\alpha \% 、 \beta \%, \gamma \%$ in terms of capital input, local labor input and the contribution of floating population to economic growth, it is assumed that under perfect competition conditions, if $\mathrm{G}_{\mathrm{t}}, \mathrm{H}_{1}, \mathrm{H}_{2}$, increase by $1 \%$, we know that there is an increase in total output $(\alpha+\beta+\gamma) \%$, so the contribution of $G_{t} 、 H_{1} 、 H_{2}$ to $P_{t}$ not is $\alpha 、 \beta 、 \gamma$, but the percent of the various parameters in $\alpha+\beta+\gamma$, The calculation expressions are respectively of $\alpha \%, \beta \% 、 \gamma \%$ is:

The contribution of investment capital to economic growth is:

$$
\alpha \%=\frac{\alpha}{\alpha+\beta+\gamma}
$$

The contribution rate of local labor input to economic growth is:

$$
\beta \%=\frac{\beta}{\alpha+\beta+\gamma}
$$

The contribution rate of floating population to economic growth is:

$$
\gamma \%=\frac{\gamma}{\alpha+\beta+\gamma}
$$

At this point we find the contribution rate of floating population to urban economic growth.

\section{Conclusions and recommendations}

Conclusion. Through theoretical analysis, we find out the floating population of urban economic growth contribution rate expression, the result shows that the floating population's contribution to the urban economic growth does not depend on the number of floating population, not the floating population, the more the greater contribution to local economic growth. Floating population has contributed by the floating population on economic growth and the output elasticity of human capital, it shows that urban economic growth need reasonable floating population, the population too little is not enough to promote economic growth, too much of the floating population will hinder economic growth.

Recommendations. Firstly, it attaches importance to the natural fusion of floating population and the integration of dry preconditions

The social integration of floating population is a natural process, with its employment, housing, communication, marriage, birth of social life and social ties expand increasingly, naturally promote social fusion process. This social integration process is manifested as part of the floating population will gradually leave the city to return to the countryside, while some of the population will gradually settle down. Excessive "fostering" of this process may not produce the kind of integration that a floating population needs. But this does not mean that the government does not need to provide for the integration of floating population in the city to promote and support of government oriented intervention can largely accelerated or integration process, including directly on the system of acceptance, the supply of public services, especially social security, including the government's support by promoting education, improve the social support of the community and provide organized way to strengthen social capital, etc. In other words, the local government should provide the integration of the dry preconditions and promote the welfare of the floating population, and guide the integration of the floating population and the local population.

Second, promote the gradual integration and multi-dimensional integration of floating population. Social integration is a process, but the way this process is developed is gradual, and it is never integrated into the degree of integration. It is necessary to maintain the direction of the process and try to move the current population along this direction to speed up integration and avoid hindering or even retrogression in this direction. At the same time, the social integration of the floating 
population includes different aspects, which will enable the floating population to begin to integrate in some aspects, while in others it may not be integrated completely. The government according to the different characteristics of the floating population groups formulate corresponding policies to promote integrated, according to the role of various factors affecting the size and importance of various factors, to boost constantly to break into the obstacles in the process of floating population into the local urban society.

\section{Acknowledgement}

Social Science Foundation of research base project of Ministry of Education,China. (15JJD790025)

\section{References}

[1] Chen fajuan. Marxist theory of population and its practical significance [J]. Journal of huainan normal university, 2011, 13(2):5-7.

[2] Zhang aiting. A review of the main population theory of western economics [J]. Productivity research, 2006(2):251-254.

[3] QiJingJing, mdi. Rural labor flow and flow across the province province attractive analysis based on traditional Labour migration, human capital and new labor migration and institutional change theory [J]. Journal of population and economy, 2013 (3) : 53-61.

[4] Wang maofu, shi zheng. The remigration of the reservoir in the context of institutional change - the improvement of the push and pull theory of migration motivation [J]. Journal of huazhong university of science and technology (social science edition), 2004, 18(3):34-38.

[5] Li shuo, zhu chu. Changes in rural women's participation and population control mechanism [J]. China population science, 1994(1):19-23.

[6] An analysis of the importance of "time" factors in the study of population migration [J]. Population research, 2000, 24(4):14-22.

[7] CAI fang. Regional characteristics of labor migration during the transition period [J]. China population science, 1998(5):18-24.

[8] Campbell, Horace (2015). Chinese Social Transformation and its Implications for African Reconstruction, Transnational Corporations Review, 7(4):365-394. 